\title{
Arterial and renal consequences of partial genetic deficiency in tissue kallikrein activity in humans
}

\author{
Michel Azizi, ${ }^{1}$ Pierre Boutouyrie, ${ }^{2}$ Alvine Bissery, ${ }^{1}$ Mohsen Agharazii, ${ }^{2}$ \\ Francis Verbeke, ${ }^{2}$ Nora Stern, ${ }^{1}$ Alessandra Bura-Rivière, ${ }^{1}$ Stéphane Laurent, ${ }^{2}$ \\ François Alhenc-Gelas, ${ }^{3}$ and Xavier Jeunemaitre ${ }^{4}$
}

${ }^{1}$ Centre d'Investigations Cliniques 9201, Assistance Publique des Hôpitaux de Paris and INSERM, ${ }^{2}$ Service de Pharmacologie and INSERM EPI U 107,
3INSERM unit 367, and ${ }^{4}$ Département de Génétique, Hôpital Européen Georges Pompidou, Université Paris V, Paris, France.

\begin{abstract}
Tissue kallikrein (TK), the major kinin-forming enzyme, is synthesized in several organs, including the kidney and arteries. A loss-of-function polymorphism of the human TK gene $(R 53 H)$ induces a substantial decrease in enzyme activity. As inactivation of the TK gene in the mouse induces endothelial dysfunction, we investigated the vascular, hormonal, and renal phenotypes of carriers of the $53 \mathrm{H}$ allele. In a crossover study, $30 R 53 R$ homozygous and $10 \mathrm{R} 53 \mathrm{H}$-heterozygous young normotensive white males were randomly assigned to receive both a low sodium-high potassium diet to stimulate TK synthesis and a high sodium-low potassium diet to suppress TK synthesis, each for 1 week. Urinary kallikrein activity was $50-60 \%$ lower in $R 53 H$ subjects than in $R 53 R$ subjects. Acute flow-dependent vasodilatation and endothelium-independent vasodilatation of the brachial artery were both unaffected in $R 53 H$ subjects. In contrast, $R 53 H$ subjects consistently exhibited an increase in wall shear stress and a paradoxical reduction in artery diameter and lumen compared with $R 53 R$ subjects. Renal and hormonal adaptation to diets was unaffected in $R 53 \mathrm{H}$ subjects. The partial genetic deficiency in TK activity is associated with an inward remodeling of the brachial artery, which is not adapted to a chronic increase in wall shear stress, indicating a new form of arterial dysfunction affecting $5-7 \%$ of white people.
\end{abstract}

\section{Introduction}

Tissue kallikrein (TK), a serine protease synthesized in many organs, cleaves low- and high-molecular-weight kininogens, thus releasing the vasodilator peptides known as kinins (1-4). The kallikrein-kinin system is present in the endothelium and in the smooth muscle of vascular walls (5-7), where locally generated kinins have potent endothelium-mediated vasodilatory and antithrombotic properties through activation of bradykinin $\mathrm{B}_{2}$ receptors, triggering NO release and other endothelial mediators $(1,8,9)$. TK is also synthesized in large amounts in the kidney connecting tubule and cortical collecting tubule and is released in the urine and the peritubular interstitium (10). The renal kallikrein-kinin system is believed to operate in concert with the renin-angiotensin system to regulate physiologically the distribution of renal blood flow $(1,11,12)$ and the metabolism of water and electrolytes (1). Urinary kallikrein activity (UKLKa) is influenced by hereditary factors $(13,14)$ and by dietary $\mathrm{Na}^{+}$and $\mathrm{K}^{+}$intake $(1)$. Family studies have demonstrated familial aggregation of UKLKa and have suggested that a large part of the observed population variance is attributable to a major gene effect (14). We recently identified a loss-of-function polymorphism in exon 3 of the TK gene. This polymorphism changes an active-site arginine at position 53 to a histidine $(R 53 H)$, resulting in a substantial loss of kallikrein activity in vitro (15). The $53 \mathrm{H}$ allele is found at a frequency of 0.03 in

Nonstandard abbreviations used: ANP, atrial natriuretic peptide; $\mathrm{Di}$, internal diameter; GTN, glyceryl trinitrate; IMT, intima media thickness; MSR, mean shear rate; MSS, mean shear stress; TK, tissue kallikrein; UKLKa, urinary kallikrein activity; WSR, wall shear rate; WBV, whole blood viscosity.

Conflict of interest: The authors have declared that no conflict of interest exists.

Citation for this article: J. Clin. Invest. 115:780-787 (2005)

doi:10.1172/JCI200523669. white people (15), and approximately $5-7 \%$ of the population are heterozygous for $53 \mathrm{H}$. On average, UKLKa is $50 \%$ lower in $\mathrm{R} 53 \mathrm{H}$ heterozygotes than in $R 53 R$-homozygous subjects, reflecting the strong functional effect of the mutation (15).

The identification of a subset of subjects with genetically reduced kallikrein activity provides an opportunity to study the physiological role of the tissue kallikrein-kinin system in humans and to assess the consequences of constitutively low kallikrein activity. Interestingly, inactivation of the TK gene in the mouse does not alter BP but does induce endothelial dysfunction and a loss of flow-mediated vasodilatation, an important adaptive process controlling blood delivery to organs, in both conductance and resistance arteries $(3,7,16)$.

We thus investigated the arterial, renal, and hormonal phenotypes of $53 \mathrm{H}$ allele carriers. We studied these subjects on an ad libitum diet and then on controlled diets with high and low $\mathrm{Na}^{+}$and $\mathrm{K}^{+}$content to modulate the level of kallikrein synthesis and excretion $(17,18)$ and to monitor physiological adaptation to these diets. We found that a decrease in TK activity resulting from a genetic mutation in humans is associated with a newly discovered form of arterial dysfunction characterized by an inward remodeling of the brachial artery, which is not adapted to a chronic increase in wall shear stress.

\section{Results}

Consequences of the R53H polymorphism on UKLKa. UKLKa followed a circadian cycle with a large decrease during the night (Table 1), as reported previously (19). The changes in $\mathrm{Na}^{+} / \mathrm{K}^{+}$intake were accompanied by substantial changes in the 24-hour UKLKa (Table 1): compared with the 24-hour UKLKa of subjects measured at baseline on the ad libitum diet, the 24-hour UKLKa increased by 
Table 1

UKLKa and $\mathrm{Na}^{+}$and $\mathrm{K}^{+}$excretion

\begin{tabular}{|c|c|c|c|c|}
\hline & Baseline & Low $\mathrm{Na}^{+}-$high $\mathrm{K}^{+}$diet & High $\mathrm{Na}^{+}-$low $\mathrm{K}^{+}$diet & $P$ value between the 2 diets \\
\hline \multicolumn{5}{|c|}{ 24-hour UKLKa ( $\Delta \mathrm{FU} / \mathrm{s} / 24$ h) } \\
\hline$R 53 H(n=10)$ & $5228[2084 ; 6630]$ & 20017 [14536;24872] & $1759[403 ; 4950]$ & $<0.0001$ \\
\hline$R 53 R(n=30)$ & $14534[6700 ; 26118]$ & $51515[32557 ; 84699]$ & $2560[222 ; 10773]$ & $<0.0001$ \\
\hline$P$ value $R 53 H$ vs. $R 53 R$ & 0.006 & 0.0045 & 0.26 & \\
\hline \multicolumn{5}{|c|}{ 12-hour daytime UKLKa ( $\Delta \mathrm{FU} / \mathrm{s} / 12 \mathrm{~h})$} \\
\hline$R 53 H(n=10)$ & $4490[1063 ; 6286]$ & $13460[12052 ; 20276]$ & $1383[81 ; 3294]$ & $<0.0001$ \\
\hline$R 53 R(n=30)$ & $9336[3951 ; 20051]$ & 38119 [24806;62239] & $2550[70 ; 10594]$ & $<0.0001$ \\
\hline$P$ value $R 53 H$ vs. $R 53 R$ & 0.053 & 0.006 & 0.16 & \\
\hline \multicolumn{5}{|c|}{ 12-hour night-time UKLKa ( $\Delta \mathrm{FU} / \mathrm{s} / 12 \mathrm{~h})$} \\
\hline$R 53 H(n=10)$ & $15[11 ; 203]$ & $3854[735 ; 7805]$ & $18[13 ; 2437]$ & $<0.0001$ \\
\hline$R 53 R(n=30)$ & $2171[9 ; 7988]$ & 9027 [1203;27493] & $14[9 ; 28]$ & $<0.0001$ \\
\hline$P$ value $R 53 H$ vs. $R 53 R$ & 0.07 & 0.13 & 0.28 & \\
\hline \multicolumn{5}{|c|}{ 24-hour urine volume (ml) } \\
\hline$R 53 H(n=10)$ & $1995[602 ; 2820]$ & $1931[810 ; 4225]$ & $1914[1476 ; 2964]$ & 0.60 \\
\hline$R 53 R(n=30)$ & $1497[720 ; 2627]$ & $2362[849 ; 4326]$ & 2108 [1028;3473] & 0.19 \\
\hline$P$ value $R 53 H$ vs. $R 53 R$ & 0.16 & 0.40 & 0.60 & \\
\hline \multicolumn{5}{|c|}{ 24-hour urinary $\mathrm{Na}^{+}$excretion (mmol/24 h) } \\
\hline$R 53 H(n=10)$ & $142[110 ; 179]$ & $19[14 ; 22]$ & $242[210 ; 263]$ & $<0.0001$ \\
\hline$R 53 R(n=30)$ & $160[133 ; 188]$ & $17[12 ; 21]$ & $265[226 ; 300]$ & $<0.0001$ \\
\hline$P$ value $R 53 H$ vs. $R 53 R$ & 0.40 & 0.60 & 0.20 & \\
\hline \multicolumn{5}{|c|}{ 24-hour urinary $\mathrm{K}^{+}$excretion (mmol/24 h) } \\
\hline$R 53 H(n=10)$ & $67[59 ; 85]$ & $104[96 ; 134]$ & $38[31 ; 40]$ & $<0.0001$ \\
\hline$R 53 R(n=30)$ & $69[60 ; 81]$ & $128[107 ; 139]$ & $40[31 ; 44]$ & $<0.0001$ \\
\hline$P$ value $R 53 H$ vs. $R 53 R$ & 0.70 & 0.30 & 0.50 & \\
\hline
\end{tabular}

Data are expressed as median and interquartile range (in square brackets, separated by a semicolon).

4.5-fold (interquartile range, 2.8-7) when the subjects received the low $\mathrm{Na}^{+}$-high $\mathrm{K}^{+}$diet and decreased by 3.2 -fold (interquartile range, 1.1-22) when they received the high $\mathrm{Na}^{+}-$low $\mathrm{K}^{+}$diet. The low $\mathrm{Na}^{+}$-high $\mathrm{K}^{+}$diet had no influence on the circadian cycle of UKLKa, whereas the high $\mathrm{Na}^{+}-$low $\mathrm{K}^{+}$diet amplified it by almost abolishing kallikrein excretion at night (Table 1).

The $R 53 H$ subjects had significantly lower UKLKa values than did the $R 53 R$ subjects. At baseline (i.e., on the ad libitum diet), the 24-hour UKLKa level was 50-60\% lower on average in $R 53 H$ subjects than in $R 53 R$ subjects $(P=0.006$; Table 1 and Figure 1$)$, as observed previously in other populations (15). With the low $\mathrm{Na}^{+}$-high $\mathrm{K}^{+}$diet, the absolute increment in UKLKa was smaller in the $R 53 H$ subjects than in the $R 53 R$ subjects, with the consequence that the difference between the genotypes was amplified (Table 1). Similarly, during the high $\mathrm{Na}^{+}-$low $\mathrm{K}^{+}$intake, the absolute decrease in UKLKa was less pronounced in the $R 53 H$ subjects than in the $R 53 R$ subjects, with the consequence that the genotype-related difference was blunted and was no longer statistically significant (Table 1). The between-subject variability in 24-hour UKLKa was large for the $R 53 R$ subjects in all experimental conditions and was lower for the $R 53 \mathrm{H}$ subjects. Consequently, the 24-hour UKLKa values for the 2 groups overlapped (Figure 1). UKLKa was not correlated to urine volume (not shown).

Consequences of the $\mathrm{R} 53 \mathrm{H}$ polymorphism on brachial artery function and on BP. Figure 2 shows a representative tracing of the brachial artery diameter and shear stress measured continuously. Acute postischemic flow-mediated changes in brachial artery diameter during hand hyperhemia did not significantly differ between the 2 genotypes on either $\mathrm{Na}^{+} / \mathrm{K}^{+}$diet (percent changes in artery diameter; Tables 2 and 3 and Figure 3). After 20 minutes of recovery, the endothelium-independent vasodilatory response to sublingual glyceryl trinitrate (GTN) was similar for both genotypes (percent changes in artery diameter; Tables 2

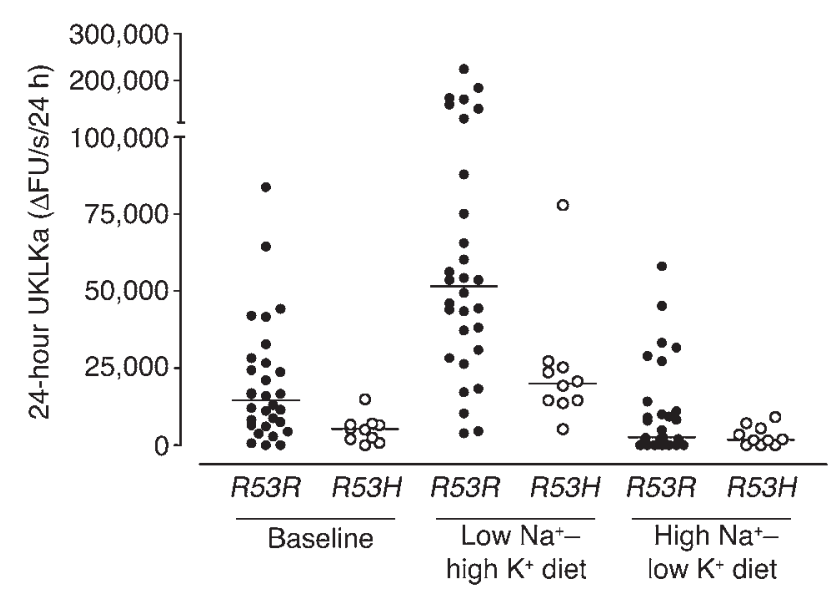

\section{Figure 1}

Effect of the $\mathrm{R} 53 \mathrm{H}$ polymorphism of the TK gene and of the $\mathrm{Na}^{+}$and $\mathrm{K}^{+}$ content of the diet on 24-hour UKLKa. R53R, filled circles; $R 53 H$, open circles. The horizontal lines indicate the median values. 
A

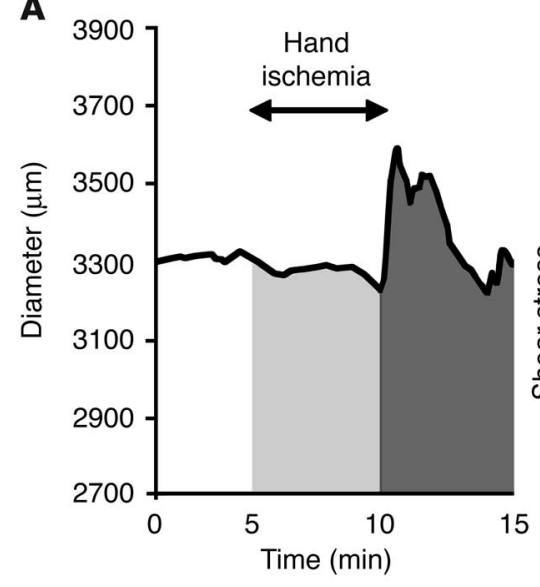

B

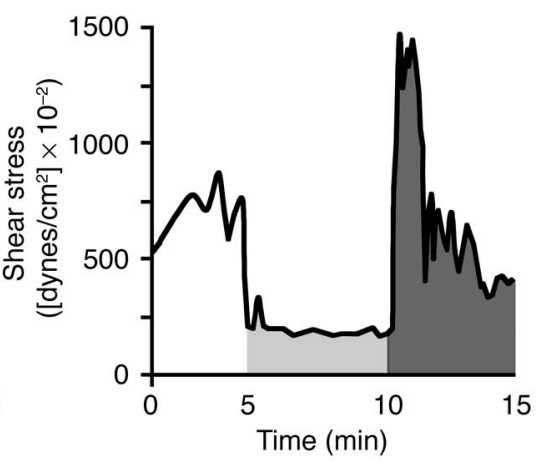

\section{Figure 2}

Evaluation of flow-mediated and endothelium-independent vasodilation. (A and B) Typical recording of the mean values of brachial artery diameter $(\mathbf{A})$ and shear stress (B) obtained at baseline (white areas) and during 5 minutes of hand ischemia (light gray areas) and hyperhemia (dark gray areas) in a healthy volunteer. and 3 and Figure 3). On average, GTN-induced vasodilatation was greater than the flow-mediated vasodilatation.

Despite showing similar acute vasodilatory responses to flow and GTN, the $R 53 H$ subjects differed from the $R 53 R$ subjects in terms of shear stress and artery morphology in all experimental conditions (baseline, hand ischemia, hand hyperhemia, and after GTN). Indeed, on the high $\mathrm{Na}^{+}-$low $\mathrm{K}^{+}$diet, the $\mathrm{R} 53 \mathrm{H}$ subjects displayed higher shear stress values and had smaller brachial artery diameter associated with similar intima media thickness, wall-to-lumen ratio, and wall cross-sectional area, thus indicating a smaller lumen than that of the R53R subjects (Table 2 and Figure 3 ). When subjects received the low $\mathrm{Na}^{+}$-high $\mathrm{K}^{+}$diet, similar results were obtained, with the $R 53 H$ subjects having significantly higher shear stress values in all experimental conditions than the R53R subjects. However, with this diet, the difference in brachial artery diameter was no longer significant between the 2 genotypes (Table 3 and Figure 3). Body surface area, known to be correlated with arterial diameter, was similar for the 2 genotypes (not shown). All results were obtained in the absence of genotype-induced differences in blood pressure (Tables 2 and 3 ).

Consequences of the R53H polymorphism on the renal and hormonal adaptation to the $\mathrm{Na}^{+} / \mathrm{K}^{+}$diets. On the ad libitum $\mathrm{Na}^{+} / \mathrm{K}^{+}$diet, $156 \mathrm{mmol}$ of $\mathrm{Na}^{+}$(interquartile range, $126-187 \mathrm{mmol}$ ) and $68 \mathrm{mmol}$ of $\mathrm{K}^{+}$(interquartile range, 59-81 $\mathrm{mmol}$ ) were excreted in the urine in 24 hours. By controlling the $\mathrm{Na}^{+} / \mathrm{K}^{+}$intakes, it was possible to achieve the desired $\mathrm{Na}^{+}$and $\mathrm{K}^{+}$balances, as reflected by 24 -hour urinary $\mathrm{NaCl}$ and $\mathrm{KCl}$ excretion rates (Table 1 ). The 24 -hour urinary $\mathrm{Na}^{+}$and $\mathrm{K}^{+}$excretion levels were identical for subjects of both genotypes for all of the diets (Table 1).

Plasma active renin, prorenin, aldosterone, and atrial natriuretic peptide (ANP), and urinary aldosterone concentrations on the ad libitum

\section{Blood pressure}

\section{Table 2}

Flow-mediated and endothelium-independent vasodilatation in $R 53 H$ and $R 53 R$ subjects receiving the high $\mathrm{Na}^{+}-$low $\mathrm{K}^{+}$diet

$\mathrm{Na}^{+} / \mathrm{K}^{+}$diet were within the physiological range and did not differ according to genotype (Table 4). As expected, plasma active renin and prorenin, and plasma and urinary aldosterone concentrations increased with the low $\mathrm{Na}^{+}$-high $\mathrm{K}^{+}$diet and decreased with the high $\mathrm{Na}^{+}-$low $\mathrm{K}^{+}$diet. The changes in plasma ANP concentrations were in the opposite directions (Table 4).

\section{jects receiving the high Nat-low $K+$ diet}

\section{R53H heterozygotes}

$(n=10)$

Systolic blood pressure $(\mathrm{mmHg})$ Diastolic blood pressure $(\mathrm{mmHg})$ Heart rate (bpm)

\section{Flow-mediated vasodilatation}

\section{Baseline}

Brachial artery diameter ( $\mu \mathrm{m})$ Intima media thickness $(\mu \mathrm{m})$ Wall-to-lumen ratio (\%) Wall cross-sectional area $\left(\mathrm{mm}^{2}\right)$ Shear stress $\left(\left[\right.\right.$ dynes $\left.\left./ \mathrm{cm}^{2}\right] \times 10^{-2}\right)$

\section{Hand ischemia}

Brachial artery diameter $(\mu \mathrm{m})$ Shear stress $\left(\left[\right.\right.$ dynes $\left.\left./ \mathrm{cm}^{2}\right] \times 10^{-2}\right)$

\section{Hand hyperhemia}

Brachial artery diameter ( $\mu \mathrm{m})$

Shear stress $\left(\left[\right.\right.$ dynes $\left.\left./ \mathrm{cm}^{2}\right] \times 10^{-2}\right)$

Change in artery diameter (\%)

\section{Endothelium-independent vasodilatation}

\section{Baseline}

Brachial artery diameter $(\mu \mathrm{m})$ Shear stress $\left(\left[\right.\right.$ dynes $\left.\left./ \mathrm{cm}^{2}\right] \times 10^{-2}\right)$

\section{After GTN}

Brachial artery diameter ( $\mu \mathrm{m})$ Shear stress $\left(\left[\right.\right.$ dynes $\left.\left./ \mathrm{cm}^{2}\right] \times 10^{-2}\right)$ Change in artery diameter (\%)

$$
\begin{gathered}
115[112 ; 117] \\
60[57 ; 64] \\
57[56 ; 66]
\end{gathered}
$$

Data are expressed as median and interquartile range.

$\begin{array}{ccc}3647[3453 ; 4005] & 4095[3848 ; 4222] & 0.053 \\ 411[377 ; 431] & 405[380 ; 412] & 0.74 \\ 22.1[18.4 ; 25.6] & 20.2[18.1 ; 21.6] & 0.16 \\ 4.35[3.93 ; 4.82] & 4.61[4.42 ; 5.25] & 0.15 \\ 399[321 ; 614] & 296[234 ; 386] & 0.017 \\ & & \\ 3640[3355 ; 3966] & 4063[3820 ; 4202] & 0.036 \\ 271[194 ; 410] & 158[137 ; 187] & 0.0009 \\ & & \\ 3691[3450 ; 3980] & 4114[3889 ; 4238] & 0.036 \\ 488[352 ; 756] & 371[268 ; 461] & 0.03 \\ 3.7[1.7 ; 4.6] & 2.9[1.6 ; 4] & 0.70\end{array}$

$\begin{array}{ccc}3667[3365 ; 3960] & 4097[3836 ; 4261] & 0.046 \\ 408[346 ; 644] & 288[247 ; 355] & 0.005 \\ & & \\ 4393[4254 ; 4668] & 4742[4463 ; 5021] & 0.07 \\ 373[292 ; 526] & 261[238 ; 338] & 0.049 \\ 20[17 ; 25] & 17[13 ; 21] & 0.18\end{array}$

0.73

0.85

0.10 $(n=30)$

$59[56 ; 62]$

$56[53 ; 62]$ 


\section{Table 3}

Flow-mediated and endothelium-independent vasodilatation in $R 53 H$ and $R 53 R$ subjects receiving the low $\mathrm{Na}^{+}-$high $\mathrm{K}^{+}$diet

\begin{tabular}{|c|c|c|c|}
\hline & $\begin{array}{l}R 53 H \text { heterozygotes } \\
\qquad(n=10)\end{array}$ & $\begin{array}{l}R 53 R \text { homozygotes } \\
\qquad(n=30)\end{array}$ & $P$ value \\
\hline \multicolumn{4}{|l|}{ Blood pressure } \\
\hline $\begin{array}{l}\text { Systolic blood pressure }(\mathrm{mmHg}) \\
\text { Diastolic blood pressure }(\mathrm{mmHg}) \\
\text { Heart rate }(\mathrm{bpm})\end{array}$ & $\begin{array}{c}115[113 ; 119] \\
58[56 ; 63] \\
64[58 ; 68]\end{array}$ & $\begin{array}{c}114[110 ; 120] \\
61[59 ; 64] \\
59[54 ; 65]\end{array}$ & $\begin{array}{l}0.89 \\
0.18 \\
0.12\end{array}$ \\
\hline \multicolumn{4}{|l|}{ Flow-mediated vasodilatation } \\
\hline \multicolumn{4}{|l|}{ Baseline } \\
\hline $\begin{array}{l}\text { Brachial artery diameter }(\mu \mathrm{m}) \\
\text { Intima media thickness }(\mu \mathrm{m}) \\
\text { Wall-to-Iumen ratio }(\%) \\
\text { Wall cross-sectional area }\left(\mathrm{mm}^{2}\right) \\
\text { Shear stress }\left(\left[\text { dynes } / \mathrm{cm}^{2}\right] \times 10^{-2}\right)\end{array}$ & $\begin{array}{c}3724[3458 ; 4065] \\
411[377 ; 432] \\
0.21[0.19 ; 0.25] \\
4.38[3.90 ; 4.87] \\
468[339 ; 636]\end{array}$ & $\begin{array}{c}3967[3669 ; 4384] \\
405[380 ; 413] \\
0.21[0.18 ; 0.22] \\
4.56[4.16 ; 5.00] \\
277[226 ; 383]\end{array}$ & $\begin{array}{c}0.25 \\
0.75 \\
0.91 \\
0.51 \\
0.025\end{array}$ \\
\hline \multicolumn{4}{|l|}{ Hand ischemia } \\
\hline $\begin{array}{l}\text { Brachial artery diameter }(\mu \mathrm{m}) \\
\text { Shear stress }\left(\left[\text { dynes } / \mathrm{cm}^{2}\right] \times 10^{-2}\right)\end{array}$ & $\begin{array}{c}3652[3431 ; 4031] \\
246[179 ; 286]\end{array}$ & $\begin{array}{c}3942[3600 ; 4354] \\
171[128 ; 225]\end{array}$ & $\begin{array}{l}0.20 \\
0.027\end{array}$ \\
\hline \multicolumn{4}{|l|}{ Hand hyperhemia } \\
\hline $\begin{array}{l}\text { Brachial artery diameter }(\mu \mathrm{m}) \\
\text { Shear stress }\left(\left[\text { dynes } / \mathrm{cm}^{2}\right] \times 10^{-2}\right) \\
\text { Change in artery diameter }(\%)\end{array}$ & $\begin{array}{c}3751[3496 ; 4106] \\
535[414 ; 759] \\
4.4[1.8 ; 6.8]\end{array}$ & $\begin{array}{c}4002[3691 ; 4398] \\
346[274 ; 490] \\
2.8[2 ; 4.6]\end{array}$ & $\begin{array}{l}0.30 \\
0.02 \\
0.50\end{array}$ \\
\hline \multicolumn{4}{|c|}{ Endothelium-independent vasodilatation } \\
\hline \multicolumn{4}{|l|}{ Baseline } \\
\hline $\begin{array}{l}\text { Brachial artery diameter }(\mu \mathrm{m}) \\
\text { Shear stress }\left(\left[\text { dynes } / \mathrm{cm}^{2}\right] \times 10^{-2}\right)\end{array}$ & $\begin{array}{c}3753[3491 ; 4130] \\
486[452 ; 633]\end{array}$ & $\begin{array}{c}3979[3725 ; 4367] \\
239[217 ; 348]\end{array}$ & $\begin{array}{c}0.30 \\
0.003\end{array}$ \\
\hline \multicolumn{4}{|l|}{ After GTN } \\
\hline $\begin{array}{l}\text { Brachial artery diameter }(\mu \mathrm{m}) \\
\text { Shear stress }\left(\left[\text { dynes } / \mathrm{cm}^{2}\right] \times 10^{-2}\right) \\
\text { Change in artery diameter }(\%)\end{array}$ & $\begin{array}{c}4538[4339 ; 4683] \\
405[262 ; 572] \\
17[13 ; 21]\end{array}$ & $\begin{array}{c}4683[4466 ; 4914] \\
250[190 ; 336] \\
18[14 ; 24]\end{array}$ & $\begin{array}{c}0.16 \\
0.027 \\
0.88\end{array}$ \\
\hline
\end{tabular}

Data are expressed as median and interquartile range. of the renal enzyme. We altered $\mathrm{Na}^{+}$and $\mathrm{K}^{+}$ intake (a) to modify renal kallikrein synthesis and to study the interaction between the $R 53 H$ polymorphism and this regulation and (b) to monitor the renal and vascular adaptations of kallikrein-deficient subjects after large variations in ionic balance. Salt restriction is known to stimulate the excretion of renal kallikrein by an unknown mechanism, possibly mediated by aldosterone $(17,18) . \mathrm{K}^{+}$ intake also upregulates kallikrein synthesis and excretion either directly or by triggering aldosterone secretion $(10,18)$. As expected, the low $\mathrm{Na}^{+}$-high $\mathrm{K}^{+}$diet strongly stimulated renal kallikrein synthesis and excretion, whereas the high $\mathrm{Na}^{+}-$low $\mathrm{K}^{+}$diet largely suppressed this excretion. The UKLKa varied by a factor of 20 between the 2 controlled diets. This allowed us to study the interaction between the $\mathrm{R} 53 \mathrm{H}$ polymorphism and the physiological regulation of renal kallikrein.

The $53 \mathrm{H}$ allele suppressed UKLKa in all conditions of $\mathrm{Na}^{+} / \mathrm{K}^{+}$intake and at all kallikrein synthesis levels, consistent with the observation that the $\mathrm{R} 53 \mathrm{H}$ mutation inactivates the catalytic activity of the enzyme in vitro (15). Our data also show that the dietinduced variations in UKLKa are blunted in $R 53 H$ subjects compared with that in $R 53 R$ subjects, as this activity varied by a factor of only 11.3 between the 2 controlled regimens in the $R 53 H$ subjects and by more than 20 -fold in the $R 53 R$ subjects. This might be because only the non-mutated allele contributes to the catalytic activity of kallikrein in $R 53 H$ subjects. These observations indicate that the $\mathrm{R} 53 \mathrm{H}$ mutation has a considerable effect on kallikrein activity levels in vivo.
The diet-induced changes in these hormonal parameters did not significantly differ between the $R 53 H$ and the $R 53 R$ subjects. The changes in 24-hour UKLKa were positively related to the changes in plasma active renin and urinary aldosterone excretion and were inversely related to changes in plasma ANP (not shown). The physiological relationship between these parameters was not influenced by the $53 \mathrm{H}$ allele.

These data collectively suggest that renal and hormonal adaptation to variations in the $\mathrm{Na}^{+} / \mathrm{K}^{+}$diet was normal in $R 53 \mathrm{H}$ subjects.

\section{Discussion}

Our results confirm that the $\mathrm{R} 53 \mathrm{H}$ kallikrein gene polymorphism (15) and the $\mathrm{Na}^{+}$and $\mathrm{K}^{+}$content of the $\operatorname{diet}(17,20-22)$ are major determinants of the level of UKLKa in physiological conditions. They also show that a $50 \%$ deficiency in TK activity that is genetically determined does not alter the capacity of the kidneys to adapt to large variations in $\mathrm{Na}^{+}$and $\mathrm{K}^{+}$intake, but triggers a peculiar form of arterial dysfunction.

We studied only white males because gender and ethnic origin are known to influence urinary kallikrein excretion $(23,24)$. We used a new kallikrein-specific enzymatic assay (25) to monitor the level of UKLKa that reflects both the activity and excretion
We observed that the renal adaptation to $\mathrm{Na}^{+}$and $\mathrm{K}^{+}$intake was not impaired in $\mathrm{R} 53 \mathrm{H}$ subjects, as their urinary electrolyte and blood pressure levels after 7 days of controlled $\mathrm{Na}^{+} / \mathrm{K}^{+}$regimens were similar to those of the R53R subjects. Furthermore, the regulation of the renin-angiotensin-aldosterone system and ANP was not altered in $R 53 H$ subjects. These results suggest that despite its abundance and high turnover rate in the kidney tubule (26) and its strong regulation by $\mathrm{Na}^{+}$and $\mathrm{K}^{+}$intake, kallikrein does not play a major role in the renal adaptation to these dietary ions, at least in the short term. An alternative explanation could be the persistence of enough residual kinin generating activity due to kallikrein in $\mathrm{R} 53 \mathrm{H}$ heterozygous subjects and/or a physiological readjustment of the kininogenkallikrein-kinin system. Changes in $\mathrm{Na}^{+}$diet in both rats and humans have indeed been shown to induce opposite changes in low-molecular-weight kininogen and in UKLKa, resulting in unchanged renal kinin concentrations (27-29). Investigation of homozygous $53 \mathrm{H}$ subjects should theoretically resolve this question, but no such subjects have been identified so far. The low frequency of the $R 53 H$ polymorphism indicates that only 1 in 2,000 white people are homozygous for the mutation. Interestingly, the renal adaptation to large variations in $\mathrm{Na}^{+}$intake was 

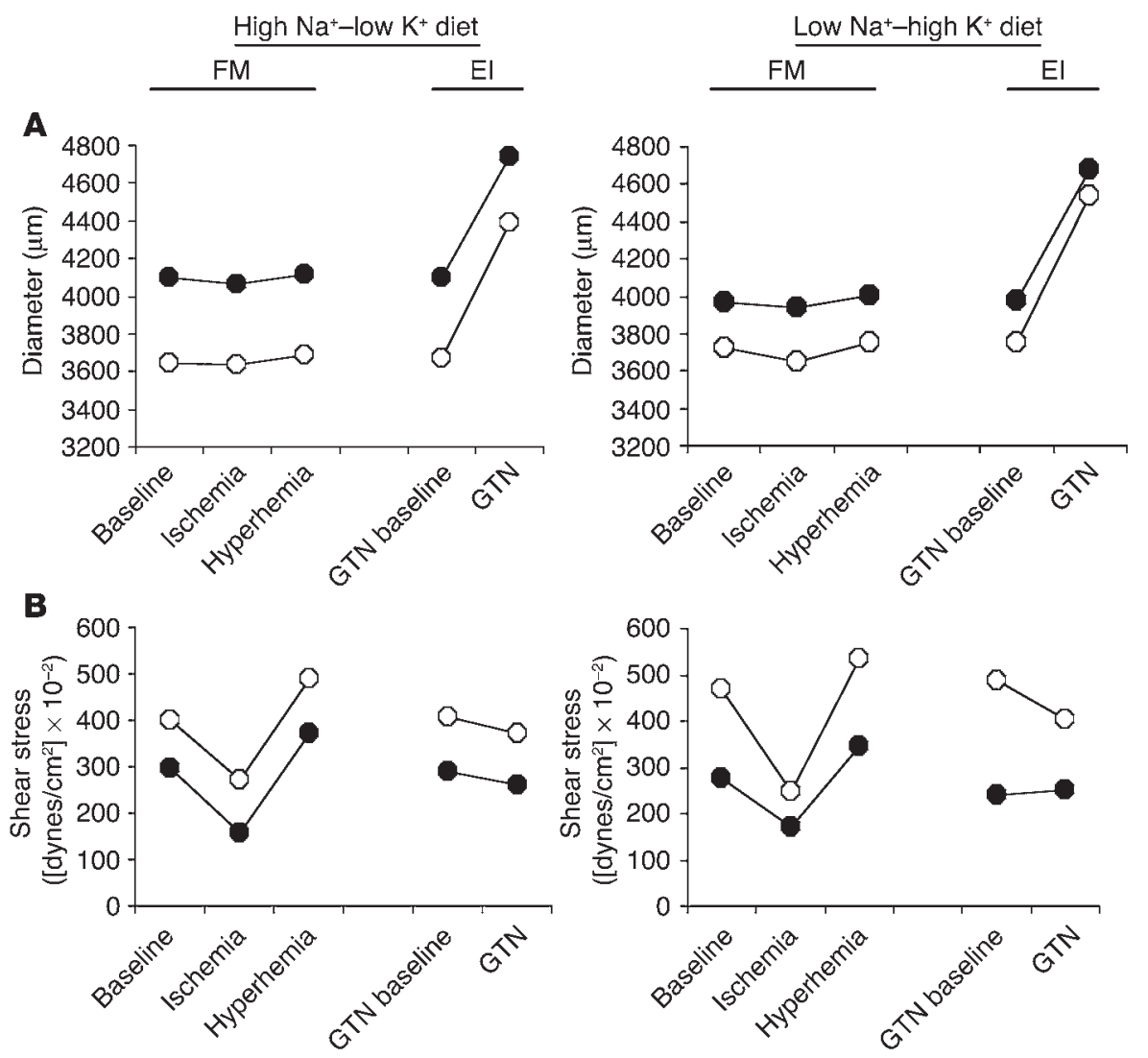

Figure 3

Diameter and shear stress responses of the brachial artery to flow and GTN administration. (A and B) Flow-mediated (FM) and endothelium-independent (EI) changes in brachial artery diameter (A) and shear stress $(\mathrm{B})$ according to genotype and to the $\mathrm{Na}^{+}$and $\mathrm{K}^{+}$content of the diet. $R 53 R$, filled circles; $R 53 H$, open circles.

found to be normal in the homozygous TK-deficient mouse (N. Picard et al., unpublished results), further suggesting that kallikrein has little, if any, role in this function.

Finally, although renal kallikrein has been suggested to be a prorenin-activating enzyme (30), the fact that plasma prorenin and active renin concentrations were not influenced by the $\mathrm{R} 53 \mathrm{H}$ polymorphism, despite a markedly reduced UKLKa, does not suggest a physiological role for kallikrein in prorenin activation. However, because of residual kallikrein activity in $R 53 H$ subjects, the possibility of this role cannot be completely ruled out.

By showing that the activity and regulation of the reninangiotensin-aldosterone system were not altered in kallikreindeficient subjects, our study reveals a physiological imbalance between the renin-angiotensin-aldosterone and kallikrein-kinin systems in these subjects. Although this physiological imbalance appears to have no consequence on the short-term renal adaptation to dietary ion intake in young male adults, it may have long-term consequences. This hormonal imbalance has indeed been observed in hypertensive patients and their normotensive offspring (31). Low UKLKa has also been associated with "nonmodulating" salt-sensitive hypertension, a phenotypic trait characterized by failure to modulate renal blood flow in response to angiotensin II after high $\mathrm{Na}^{+}$intake (32). The $R 53 H$ polymorphism may therefore predispose, in the long term, to hypertension and renal disorders associated with abnormal regulation of renal blood flow, such as diabetic nephropathy (33).

Vascular consequences of the $\mathrm{R} 53 \mathrm{H}$ polymorphism. The main finding of this study is the occurrence of arterial dysfunction in $R 53 H$ subjects.

We first showed that the acute physiological vasodilatory response to flow and the effect of direct stimulation in the smooth muscle of the cGMP-dependent pathway by GTN did not significantly differ between the 2 genotypes. Contrasting with those findings, we observed that compared to the $R 53 R$ subjects, the $R 53 H$ subjects exhibited a permanent chronic increase in shear stress associated with paradoxical reductions of the lumen and diameter of the brachial artery. The increase in shear stress was consistent across all experimental conditions. The reduction of the artery diameter was especially evident on the high $\mathrm{Na}^{+}-$low $\mathrm{K}^{+}$diet. This reduction in diameter or the simple absence of a widening of the artery despite a chronic increase in shear stress in the $R 53 H$ subjects indicates an inappropriate inward remodeling of the brachial artery in these subjects. The similarity of the intima media thickness, the wall-to-lumen ratio, and the wall crosssectional area between the 2 genotypes combined with the reduction in both the lumen and diameter of the brachial artery indicates that this artery underwent eutrophic remodeling in $R 53 H$ heterozygous subjects. When subjected to long-term changes in blood flow, arteries remodel themselves through endothelium-dependent mechanisms, thus limiting changes in wall shear stress (34). When subjected to an increase in blood flow, vascular endothelial cells release growth factors and vasoactive substances able to induce cell proliferation, migration, death, and matrix deposition $(35,36)$. In general, chronic increases in blood flow lead to outward arterial remodeling, with a widening of the lumen diameter, thus normalizing wall shear stress $(37,38)$, whereas sustained reductions in blood flow lead to inward arterial remodeling with a narrowing of lumen diameter (34). Thus, the higher wall shear stress in $R 53 H$ than in $R 53 R$ subjects, together with a paradoxical reduced internal diameter, indicates a defect in the endothelium-dependent pathways involved in arterial remodeling (35).

Our results thus show a dissociation in $R 53 H$ subjects between the acute endothelium-dependent flow-mediated response of the brachial artery (39), which appeared unchanged, and the chronic shear stress-induced endothelium-dependent arterial remodeling $(35,36)$, which appeared to be inappropriate. It remains possible that acute endothelial dysfunction occurs in $R 53 H$ subjects but is too mild to be detected in our experimental conditions, while having significant long-term consequences on arterial remodeling. Furthermore, acute endothelial dysfunction linked to genetic 
Table 4

Hormonal parameters

\section{Baseline}

\section{Low $\mathrm{Na}^{+}-$ high $\mathbf{K}^{+}$diet}

High $\mathrm{Na}^{+-} \quad P$ value between low $\mathrm{K}^{+}$diet the 2 diets

\section{Plasma active renin $(\mathrm{pg} / \mathrm{ml})$}

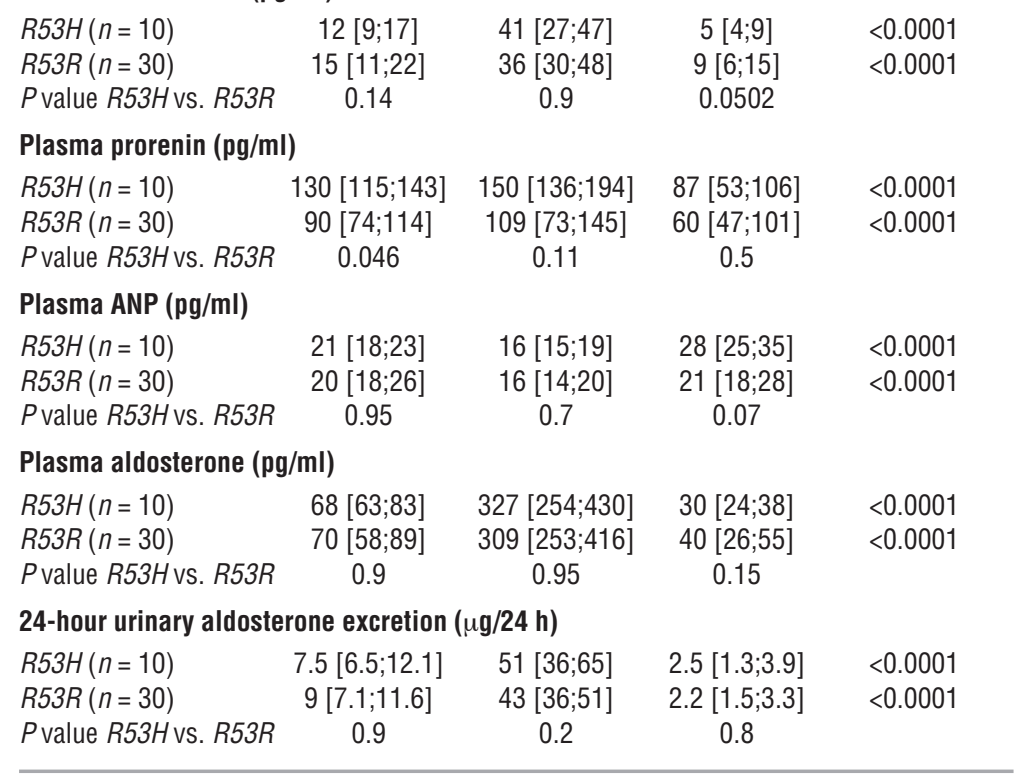

Data are expressed as median and interquartile range.

variations may be apparent only in some vascular beds; for example, at the femoral but not at the brachial artery site (40).

The observation of an abnormal arterial phenotype in subjects with a $50 \%$ deficiency in kallikrein activity is consistent with the hypothesis that the kallikrein activity level is low in arteries compared to the kidney tubule, but nevertheless plays a critical role in arterial function $(3,7)$. The physiological regulation of vascular kallikrein remains largely unknown.

Like in all human genetic association studies, we cannot completely rule out the possibility that the phenotype observed was due to a genetic variation in another gene located at the same locus. However, the observation of arterial dysfunction in mice carrying a specifically inactivated TK gene $(3,7,16)$ strongly suggests that the arterial phenotype observed in $\mathrm{R} 53 \mathrm{H}$ subjects is causally linked to kallikrein deficiency. Given the recent observation of impaired cardioprotection against ischemia in TK-deficient mice (V. Griol-Charhbili et al., manuscript submitted for publication), it would be interesting to study whether TK-deficient humans are at increased risk of cardiovascular diseases.

\section{Methods}

\section{Subjects}

We calculated that $10 \mathrm{R} 53 \mathrm{H}$ heterozygous subjects and $30 \mathrm{R} 53 \mathrm{R}$ homozygous subjects were necessary to detect a $4 \%$ difference in acute flow-mediated dilatation between $R 53 H$ and $R 53 R$ subjects, with a SD of $2.9 \%$, an $\alpha$ risk of $5 \%$ and a $\beta$ risk of $20 \%$.

We therefore screened 206 white male subjects $18-35$ years of age for the $R 53 \mathrm{H}$ genotype and the following inclusion criteria: nonsmoker, normotensive (BP less than 140/90 $\mathrm{mmHg}$ in the supine position after 5 minutes of rest), normal clinical examination, normal plasma creatinine and serum cholesterol concentrations (less than $100 \mu \mathrm{mol} / \mathrm{l}$ and less than $5.2 \mathrm{mmol} / \mathrm{l}$, respectively), and no proteinuria. Among the $11 \mathrm{R} 53 \mathrm{H}$ heterozygotes (5.3\%) detected, all except 1 smoker were included in the study. Among the remaining $R 53 R$-homozygous subjects, we included the first 30 consecutive subjects who matched all the inclusion criteria. All subjects completed the study after giving written informed consent. The protocol was approved by the "Comité Consultatif de Protection des Personnes se prêtant à des Recherches Biomédicales" (Paris-Cochin, France). All procedures were in accordance with institutional guidelines.

Study design
UKLKa and hormonal parameters were first studied
for all participants while they received an ad libitum
diet. Subjects were then randomly assigned to receive
the first of 2 experimental diets for 7 days: (a) low
$\mathrm{Na}^{+}$(less than $20 \mathrm{mmol} \mathrm{NaCl} / \mathrm{day}$ ) and high $\mathrm{K}^{+}$(more
than $140 \mathrm{mmol} \mathrm{Kcl} / \mathrm{day}$; low $\mathrm{Na}^{+}-\mathrm{high} \mathrm{K}^{+}$diet) or (b)
high $\mathrm{Na}^{+}$(more than $250 \mathrm{mmol} \mathrm{NaCl} /$ day) and low
$\mathrm{K}^{+}\left(\right.$less than $50 \mathrm{mmol} \mathrm{Kcl} / \mathrm{day}$; high $\mathrm{Na}^{+}-$low $\mathrm{K}^{+}$diet).
The order of assignment of the diets was random-
ized according a crossover study design. Controlled
$\mathrm{Na}^{+} / \mathrm{K}^{+}$diet periods were separated by a 7 -day wash-
out period. Protein and calorie intakes were kept con-
stant during the 2 periods. All meals were provided
by the metabolic kitchen of the Hôpital Européen Georges Pompidou Clinical Investigation Center and were taken in the unit. On the ad libitum $\mathrm{Na}^{+}$and $\mathrm{K}^{+}$diet and on day 7 of each controlled $\mathrm{Na}^{+} / \mathrm{K}^{+}$diet period, blood was sampled at 0900 in the fasting state after 1 hour of rest in the sitting position for plasma active and total renin and plasma aldosterone and ANP determinations. Urine was collected in 2 12-hour periods from 0800 to 2000 and from 2000 to 0800 and was used for hormone and electrolyte determinations. BP (the mean of 10 measurements performed at 2-minute intervals after 40 minutes of rest in the sitting position) was determined using an automatic validated BP recorder (Press Mate BP 8800; Colin Co.).

\section{Noninvasive measurement of flow-mediated, endothelium- dependent vasodilatation}

Endothelial function was evaluated by comparison of the endotheliumdependent vasodilatation in response to flow induced by release of a wrist cuff after a period of 5 minutes hand ischemia versus the endotheliumindependent response to sublingual GTN (39).

On day 7 of each controlled $\mathrm{Na}^{+} / \mathrm{K}^{+}$diet, after a light, caffeine-free breakfast at 0930, subjects were instructed to lie down in a temperature-controlled room $\left(21^{\circ} \mathrm{C}\right.$ to $\left.23^{\circ} \mathrm{C}\right)$ with their right arm secured comfortably on a support. The diameter and wall thickness of the brachial artery and wall shear rate were continuously measured with a high-resolution radio frequency-based vessel wall tracking system (Wall Track System; Esaote Pie-Medical) using a 7.5-Mhz ultrasound probe. Internal diameter (Di) and intima media thickness (IMT) were measured as described previously $(41,42)$. Briefly, this system uses optimized algorithms to improve the precision of interface localization, from stored high-frequency digitization of the radio frequency signal generated by reflection of ultrasound on vascular structures. The derived parameters are wall-to-lumen ratio $(2 \times \mathrm{IMT} / \mathrm{Di})$ and wall cross-sectional area $\left(\pi \times\left[(\mathrm{Di}+2 \times \mathrm{IMT})^{2}-\mathrm{Di}^{2}\right] / 4\right)$. 
Wall shear rate (WSR) in the brachial artery was determined directly (39, 43) from the radial derivative of the velocity distribution, obtained with a high-resolution multigate pulsed Doppler ultrasound system incorporated into the Wall Track system, allowing high-precision assessment of low blood flow velocities close to the wall. This method does not make the assumptions required by the Hagen-Poiseuille equation (39). Whole blood viscosity (WBV; $\mathrm{mPa} \times \mathrm{s}$ ) was estimated using the formula derived from Weaver (44-46), using hematocrit, plasma viscosity, and WSR. Mean shear stress (MSS; [dynes $\left./ \mathrm{cm}^{2}\right] \times 10^{-2}$ ) was then calculated as MSS = mean shear rate $\left(\right.$ MSR; $\left.\mathrm{s}^{-1}\right) \times$ WBV. MSR and MSS were averaged within each cardiac cycle and were acquired during 4-second periods.

Diameter and shear stress were measured at baseline (after 15 minutes of rest in the supine position), during 5 minutes of hand ischemia, during 60 and 120 seconds of reactive hand hyperemia (produced by releasing a pneumatic wrist cuff inflated to $50 \mathrm{mmHg}$ above the systolic BP for 5 minutes), and 3 minutes after the administration of $150 \mu \mathrm{g}$ GTN (Natispray $0.15 \mathrm{mg} /$ dose; Procter \& Gamble Pharmaceuticals). Post-ischemic, flow-mediated, endothelium-dependent vasodilatation was defined as the maximal increase in the brachial artery diameter during reactive hyperemia, determined as the moving average of 3 consecutive diameter measurements. All hemodynamic measurements returned to baseline 20 minutes after hand hyperemia.

The interobserver variations in baseline diameter and percentage of postocclusion vasodilatation were $0.7 \%$ and $19 \%$, respectively. To reduce bias in the reading and interpretation of the hemodynamic results, all measurements were recorded on a hard drive using random codes and were analyzed independently by 2 readers who were blinded to the genotype, the diet, and the temporal order of the measurements.

\section{Laboratory methods}

$R 53 H$ genotyping. The initial population $(n=206)$ was genotyped for the $R 53 H$ polymorphism by the mutagenically separated PCR technique (15). Each participant was genotyped a second time using a second blood sample and by direct sequencing of exon 3 of the bKLK1 gene.

Urinary kallikrein measurements. UKLKa was quantified by an amidolytic assay with the chimeric, fluorogenic peptide substrate D-PFF-Nmec (a gift from F. Gauthier, INSERM-François Rabelais University U10, Tours, France), as described previously (25). This assay is highly specific for human TK, and the substrate is not cleaved by other kallikrein-related enzymes $(15,25)$. Briefly, hydrolysis of D-PFF-NMec was measured with a Spectra Max Gemini microplate reader (Molecular Devices) by incubation of $0.02 \mathrm{ml}$ of urine for 15 minutes at $37^{\circ} \mathrm{C}$ with $0.01 \mathrm{mM}$ D-PFF-NMec in $200 \mu \mathrm{l}$ of $20 \mathrm{mM}$ Tris-HCl buffer ( $\mathrm{pH} 9.0$ ) containing $1 \mathrm{mM}$ ethylenediaminetetraacetate, as described previously $(15,25)$. Results are expressed in the change in fluorescent units per second of incubation, for the total urine collected $(\Delta \mathrm{FU} / \mathrm{s} / 12$ - or 24 -hour urine).

Hormone measurements. The methods used for collecting blood samples and for quantifying plasma active renin, total renin, ANP and aldosterone and urinary aldosterone extractable at a $\mathrm{pH}$ of 1 were as described previously (47). Prorenin level is calculated as the difference between total renin and active renin levels. All enzyme and hormone determinations were performed by experimenters blinded to genotype and order of diet.

Statistical analysis. We compared $R 53 H$ and $R 53 R$ subjects within each period of diet using the Mann-Whitney U-test. We compared the effects of diet on UKLKa and on plasma and urinary hormones using the non-parametric Wilcoxon paired test. Stata Statistical Software (version 7.0; StataCorp.) was used for statistical analysis. Data are expressed as medians and interquartile ranges. A $P$ value of less than 0.05 was considered to be significant.

\section{Acknowledgments}

The authors thank the nursing staff of the Clinical Investigation Center who ran the protocol (Danièle Ménard and Michèle Godeau) and Christiane Dollin and Rola Slim for technical help. DNA extraction and genotyping were performed by members of the Department of Genetics: Sylvie Cotigny, Valerie Nau, and Isabelle Roncelin, under the supervision of Anne-Paule GimenezRoqueplo. The authors thank Brigitte Laloux for technical assistance in arterial measurements. Kallikrein activity measurements were performed with the advice of Francis Gauthier, INSERMFrançois Rabelais University U10, Tours, France. This work was supported by a joint grant from the French Ministry of Research (ACI 2000; 1A009G00A), a grant from Assistance Publique des Hôpitaux de Paris (PHRC regional 2001; AOR\#01050), and a grant from the European Vascular Genomics Network, a Network of Excellence supported by the European Community's sixth Framework Program for Research Priority 1 "Life sciences, genomics and biotechnology for health” (Contract no. LSHM-CT-2003-503254). General support was provided by INSERM, Association Claude Bernard, and Association Naturalia et Biologia.

Received for publication October 19, 2004, and accepted in revised form December 7, 2004.

Address correspondence to: Michel Azizi, Centre d'Investigations Cliniques, AP-HP/INSERM, Hôpital Européen Georges Pompidou, 20 40 rue Leblanc, 75908 Paris cedex 15, France. Phone: 33-156-09-29-11; Fax: 33-156-09-29-29; E-mail: michel.azizi@egp.ap-hop-paris.fr.
1. Carretero, O.A., and Scicli, A.G. 1995. The kallikrein-kinin system as a regulator of cardiovascular and renal function. In Hypertension: pathophysiology, diagnosis, and management. J.H. Laragh and B.M. Brenner, editors. Raven Press. New York, New York, USA. 983-999.

2. Hecquet, C., Tan, F., Marcic, B.M., and Erdos, E.G. 2000. Human bradykinin $\mathrm{B}(2)$ receptor is activated by kallikrein and other serine proteases. Mol. Pharmacol. 58:828-836.

3. Meneton, P., et al. 2001. Cardiovascular abnormalities with normal blood pressure in tissue kallikrein-deficient mice. Proc. Natl. Acad. Sci. U. S. A. 98:2634-2639.

4. Skidgel, R.A., Alhenc-Gelas, F., and Campbell, W.B. 2003. Prologue: kinins and related systems. New life for old discoveries. Am. J. Physiol. Heart Circ. Physiol. 284:H1886-H1891.

5. Oza, N.B., Schwartz, J.H., Goud, H.D., and Levinsky, N.G. 1990. Rat aortic smooth muscle cells in culture express kallikrein, kininogen, and bradyki- ninase activity. J. Clin. Invest. 85:597-600

6. Yayama, K., Kunimatsu, N., Teranishi, Y., Takano, M., and Okamoto, H. 2003. Tissue kallikrein is synthesized and secreted by human vascular endothelial cells. Biochim. Biophys. Acta. 1593:231-238.

7. Bergaya, S., et al. 2001. Decreased flow-dependent dilation in carotid arteries of tissue kallikreinknockout mice. Circ. Res. 88:593-599.

8. Margolius, H.S. 1995. Theodore Cooper Memorial Lecture. Kallikreins and kinins. Some unanswered questions about system characteristics and roles in human disease. Hypertension. 26:221-229.

9. Linz, W., Wiemer, G., Gohlke, P., Unger, T., and Scholkens, B.A. 1995. Contribution of kinins to the cardiovascular actions of angiotensin-converting enzyme inhibitors. Pharmacol. Rev. 47:25-49.

10. Vio, C.P. 1990. Renal kallikrein. In Hypertension: pathophysiology, diagnosis, and management. J.H. Laragh and B.M. Brenner, editors. Raven Press. New York, New York, USA. 819-828.

11. Levy, S.B., Lilley, J.J., Frigon, R.P., and Stone, R.A.
1977. Urinary kallikrein and plasma renin activity as determinants of renal blood flow. The influence of race and dietary sodium intake. J. Clin. Invest. 60:129-138.

12. Siragy, H.M., Jaffa, A.A., Margolius, H.S., and Carey, R.M. 1996. Renin-angiotensin system modulates renal bradykinin production. Am. J. Physiol. 271:R1090-R1095.

13. Zinner, S.H., Margolius, H.S., Rosner, B., Keiser, H.R., and Kass, E.H. 1976. Familial aggregation of urinary kallikrein concentration in childhood: relation to blood pressure, race and urinary electrolytes. Am. J. Epidemiol. 104:124-132.

14. Berry, T.D., et al. 1989. A gene for high urinary kallikrein may protect against hypertension in Utah kindreds. Hypertension. 13:3-8.

15. Slim, R., et al. 2002. Loss-of-function polymorphism of the human kallikrein gene with reduced urinary kallikrein activity. J. Am. Soc. Nephrol. 13:968-976.

16. Bergaya, S., Matrougui, K., Meneton, P., Henrion, 
D., and Boulanger, C.M. 2004. Role of tissue kallikrein in response to flow in mouse resistance arteries. J. Hypertens. 22:745-750.

17. Margolius, H.S., Horwitz, D., Pisano, J.J., and Keiser, H.R. 1974. Urinary kallikrein excretion in hypertensive man. Relationships to sodium intake and sodium-retaining steroids. Circ. Res. 35:820-825.

18. Horwitz, D., Margolius, H.S., and Keiser, H.R. 1978. Effects of dietary potassium and race on urinary excretion of kallikrein and aldosterone in man. J. Clin. Endocrinol. Metab. 47:296-299.

19. Abe, K., et al. 1981. A circadian variation in the excretion of urinary kinin, kallikrein and prostaglandin $\mathrm{E}$ in normal volunteers. Jpn. Circ. J. 45:1098-1103.

20. Hunt, S.C., Wu, L.L., Slattery, M.L., Meikle, A.W., and Williams, R.R. 1993. Environmental determinants of urinary kallikrein excretion. Am.J. Hypertens. 6:226-233.

21. Hunt, S.C., Hasstedt, S.J., Wu, L.L., and Williams, R.R. 1993. A gene-environment interaction between inferred kallikrein genotype and potassium. Hypertension. 22:161-168.

22. Katori, M., and Majima, M. 2003. The renal kallikrein-kinin system: its role as a safety valve for excess sodium intake, and its attenuation as a possible etiologic factor in salt-sensitive hypertension. Crit. Rev. Clin. Lab. Sci. 40:43-115.

23. Kailasam, M.T., et al. 1998. Racial differences in renal kallikrein excretion: effect of the ovulatory cycle. Kidney Int. 54:1652-1658.

24. Song, C.K., et al. 2000. Renal kallikrein excretion: role of ethnicity, gender, environment, and genetic risk of hypertension. J. Hum. Hypertens. 14:461-468.

25. Bourgeois, L., et al. 1997. Serpin-derived peptide substrates for investigating the substrate specificity of human tissue kallikreins hK1 and hK2. J. Biol. Chem. 272:29590-29595.
26. Marchetti, J., et al. 1984. Kallikrein along the rabbit microdissected nephron: a micromethod for its measurement. Effect of adrenalectomy and DOCA treatment. Pflugers Arch. 401:27-33.

27. Wang, C., Chao, C., Chen, L.M., Chao, L., and Chao, J. 1996. High-salt diet upregulates kininogen and downregulates tissue kallikrein expression in Dahl-SS and SHR rats. Am. J. Physiol. 271:F824-F830.

28. Hilgenfeldt, U., et al. 1998. Low-salt diet downregulates plasma but not tissue kallikreinkinin system. Am. J. Physiol. 275:F88-F93.

29. Murphey, L.J., Eccles, W.K., Williams, G.H., and Brown, N.J. 2004. Loss of sodium modulation of plasma kinins in human hypertension. J. Pharmacol. Exp. Ther. 308:1046-1052.

30. Sealey, J.E., Atlas, S.A., Laragh, J.H., Oza, N.B., and Ryan, J.W. 1978. Human urinary kallikrein converts inactive to active renin and is a possible physiological activator of renin. Nature. 275:144-145.

31. Sanchez, R., Nolly, H., Giannone, C., Baglivo, H.P., and Ramirez, A.J. 2003. Reduced activity of the kallikrein-kinin system predominates over reninangiotensin system overactivity in all conditions of sodium balance in essential hypertensives and family-related hypertension. J. Hypertens. 21:411-417.

32. Fisher, N.D., et al. 1999. Altered adrenal sensitivity to angiotensin II in low-renin essential hypertension. Hypertension. 34:388-394.

33. Marre, M., et al. 1999. Renal changes on hyperglycemia and angiotensin-converting enzyme in type 1 diabetes. Hypertension. 33:775-780.

34. Langille, B.L., and O'Donnell, F. 1986. Reductions in arterial diameter produced by chronic decreases in blood flow are endothelium-dependent. Science. 231:405-407.

35. Davies, P.F. 1995. Flow-mediated endothelial mechanotransduction. Physiol. Rev. 75:519-560.

36. Lehoux, S., and Tedgui, A. 1998. Signal transduction of mechanical stresses in the vascular wall. Hypertension. 32:338-345.
37. Ben Driss, A., Benessiano, J., Poitevin, P., Levy, B.I., and Michel, J.B. 1997. Arterial expansive remodeling induced by high flow rates. Am. J. Physiol. 272:H851-H858.

38. Girerd, X., et al. 1996. Remodeling of the radial artery in response to a chronic increase in shear stress. Hypertension. 27:799-803.

39. Hoeks, A.P., Samijo, S.K., Brands, P.J., and Reneman, R.S. 1995. Noninvasive determination of shear-rate distribution across the arterial lumen. Hypertension. 26:26-33.

40. Arcaro, G., et al. 2001. ACE genotype and endothelium-dependent vasodilation of conduit arteries and forearm microcirculation in humans. Arterioscler. Thromb. Vasc. Biol. 21:1313-1319.

41. Boutouyrie, P., et al. 1999. Association between local pulse pressure, mean blood pressure, and largeartery remodeling. Circulation. 100:1387-1393.

42. Boutouyrie, P., et al. 2000. Local pulse pressure and regression of arterial wall hypertrophy during long-term antihypertensive treatment. Circulation. 101:2601-2606.

43. Brands, P.J., Hoeks, A.P., Hofstra, L., and Reneman, R.S. 1995. A noninvasive method to estimate wall shear rate using ultrasound. Ultrasound Med. Biol. 21:171-185.

44. Weaver, J.P., Evans, A., and Walder, D.N. 1969. The effect of increased fibrinogen content on the viscosity of blood. Clin. Sci. 36:1-10.

45. Brooks, D.E., Goodwin, J.W., and Seaman, G.V. 1970. Interactions among erythrocytes under shear. J. Appl. Physiol. 28:172-177.

46. Samijo, S.K., et al. 1998. Wall shear stress in the human common carotid artery as function of age and gender. Cardiovasc. Res. 39:515-522.

47. Massien, C., et al. 1999. Pharmacodynamic effects of dual neutral endopeptidase-angiotensin- converting enzyme inhibition versus angiotensin-converting enzyme inhibition in humans. Clin. Pharmacol. Ther. 65:448-459. 